\title{
Pockennarben und Schönheit
}

\author{
Von Huldrych M. Koelbing
}

Wie die Pocken den Liebreiz eines Frauengesichtes vernichten und dadurch eine persönliche Tragödie einleiten konnten, dafür gibt Theodor Fontane in seiner 1882 erschienenen Novelle «Schach von Wuthenow» ein Beispiel. Er selbst faßt seine Erzählung folgendermaßen zusammen ${ }^{1}$ : «Sie ... spielt in der Zeit von 1805 auf 6 und schildert den schönsten Offizier der damaligen Berliner Garnison, der, in einem Anfall von Übermut und Laune, die liebenswürdigste, aber häßlichste junge Dame der damaligen Hofgesellschaft becourt. So, daß der Skandal offenbar wird. Alles tritt auf die Seite der Dame, so daß sich v. Schach anscheinend freudig zur Hochzeit entschließt, nachdem er vorher durch allerlei Kämpfe gegangen. Die Kameradschaft vom Regiment Gensdarmes aber lacht und zeichnet Karikaturen, und weil er dies Lachen nicht ertragen kann, erschießt er sich unmittelbar nach dem Hochzeitsmahl, an dem er in heitrer Ruhe teilgenommen. Alles ein Produkt der Zeit, ihrer Anschauungen, Eitelkeiten und Vorurteile. Übrigens alles Tatsache.»

Für sich allein betrachtet, hätte die Begebenheit den Stoff für eine aufgedonnerte und kitschige "wahre Geschichte» abgeben können; Fontane aber macht daraus eine Zeit- und Charakterstudie von Rang - das zeigt schon die zitierte Briefstelle. Die Bemerkung «übrigens alles Tatsache» ist wohl nicht buchstäblich zu nehmen. «Daß ich alles frei behandelt habe, versteht sich von selbst», schreibt Fontane etwas später an Mathilde von Rohr, der er den Stoff verdankte. Was Fontane in seiner gedrängten Inhaltsübersicht nicht erwähnt, ist der Umstand, daß der Held seiner Novelle die junge Dame schon vor ihrer Erkrankung gekannt und ihrer Schönheit wegen bewundert hatte.

So eklatante Dramen wie das von Fontane entwickelte dürften selten gewesen sein; aber viel stilles Leid ist sicher durch Pockennarben verursacht worden. Doch die Not ließ sich auch in den Dienst der Tugend stellen, wie es in den beiden hier nun folgenden Kinderliedern aus dem späteren 18. Jahrhundert versucht wurde. Diese Lieder sind von Johann Adam Hiller (1728 bis 1804) vertont worden, doch der Verfasser der Texte blieb anonym ${ }^{3}$. Sein Drang, die kindlichen Gemüter moralisch zu veredeln, scheint mir stärker gewesen zu sein als seine dichterische Kraft. Das Bändchen, dem ich die Verse entnehme, erhielt ein dreizehnjähriger Basler Junge, Johann Rudolf 
Huber (1766-1806), später Pfarrer in Straßburg, Riehen und Basel, im Jahre 1779 von einem seiner Lehrer mit einer schönen lateinischen Widmung als «praemiolum» für seine Leistungen und seinen Fleiß in der Schule geschenkt.

\section{Eitle Schönheit}

\section{Der Bruder}

O! ich bin doch ein schöner Knabe!

$\mathrm{Ja}$ ja, das ist gewiß!

Der Spiegel, den ich vor mir habe,

Sagt augenscheinlich dies,

Wie sanft ist mein Gesicht! wie rund!

Die blauen Augen schmachten!

Und dieser kleine rothe Mund

Ist auch nicht zu verachten.

So bald ich freundlich lächle, prangen

Die Zähn, als Elfenbein,

Auf Ros und Lilienvollen Wangen

Drückt sich ein Grübchen ein,

Und ach! das güldne Haar: so soll

Ein paar der schönsten Knaben,

(Sie hießen Bacchus und Apoll)

Es einst getragen haben.

\section{Die Schwester}

Mein lieber Bruder, vor dem Jahre

War ich, wie du, so schön.

Was hatt' ich da für schwarze Haare?

Du hast sie noch gesehn.

Da lobte jeder dies Gesicht

Bewundernd, um die Wette,

Und schwur, es sey kein Mädchen nicht

So schön, als Henriette.

Allein die Schönheit ist vergangen.

Da kam der Blattern Wut,

Zerriß mir diese glatten Wangen,

Löscht' aus der Augen Glut:

Doch glaube nicht, daß michs verdrüßt.

Nein, es hat mich gelehret,

$\mathrm{Da}$ das nur wahre Schönheit ist,

Was keine Zeit zerstöret. 
In der Erziehung des Herrn Schach von Wuthenow scheinen diese erbaulichen Hiller-Lieder keine Rolle gespielt zu haben!

\section{Anmerkungen}

${ }^{1}$ Brief vom 31.Jan. 1882 an den Redakteur Julius Grosser, zit. nach: Theodor Fontane, Der Dichter über sein Werk, hrsg. von Richard Brinkmann in Zusammenarbeit mit Waltraud Wiethölter, DTV, München 1977, Bd.2, S. 296 (Erstausgabe Heimeran, München 1973).

${ }^{2}$ Brief vom 13.Juli 1882, a.a.O., S.297. Vgl. dazu: Walter Müller-Seidel, Theodor Fontane, soziale Romankunst in Deutschland, Metzler, Stuttgart 1975, S. 132-151.

${ }^{3}$ Lieder für Kinder, vermehrte (2.) Auflage. Mit Melodien von Johann Adam Hiller. Leipzig 1775, S. 50-53.

Prof. Dr. med. Huldrych M. Koelbing

Medizinhistorisches Institut

Rämistraße 71

CH-8006 Zürich 